\title{
Novel algorithms for the pragmatic use of ultrasound in the management of patients with rheumatoid arthritis: from diagnosis to remission
}

\author{
Maria Antonietta D'Agostino, ${ }^{1,2,3}$ Lene Terslev, ${ }^{4,5}$ Richard Wakefield, ${ }^{3,6}$ \\ Mikkel Østergaard, ${ }^{4,5}$ Peter Balint, ${ }^{7}$ Esperanza Naredo, ${ }^{8}$ Annamaria lagnocco, ${ }^{9}$ \\ Marina Backhaus, ${ }^{10}$ Walter Grassi, ${ }^{11}$ Paul Emery ${ }^{3,6}$
}

\begin{abstract}
Handling editor Tore K Kvien
- Additional material is published online only. To view please visit the journal online (http://dx.doi.org/10.1136/ annrheumdis-2016-209646).

For numbered affiliations see end of article.

\section{Correspondence to} Professor Paul Emery, University of Leeds, Chapel Allerton Hospital, Chapeltown Road, Leeds, LS7 4SA, UK; p.emery@leeds.ac.uk
\end{abstract}

Received 31 March 2016 Revised 29 July 2016 Accepted 31 July 2016 Published Online First 23 August 2016

\section{ABSTRACT}

The absence of specific guidance on how to use ultrasound (US) to diagnose and manage patients with inflammatory arthritis, especially with rheumatoid arthritis (RA) has hindered the optimal utilisation of US in clinical practice, potentially limiting its benefits for patient outcomes. In view of this, a group of musculoskeletal US experts formed a working group to consider how this unmet need could be satisfied and to produce guidance (additional to European League against Rheumatism (EULAR) imaging recommendations) to support clinicians in their daily clinical work. This paper describes this process and its outcome, namely five novel algorithms, which identify when US could be used. They are designed to aid diagnosis, to inform assessment of treatment response/disease monitoring and to evaluate stable disease state or remission in patients with suspected or established RA, by providing a pragmatic template for using US at certain time points of the RA management. A research agenda has also been defined for answering unmet clinical needs.

Recently, the European League against Rheumatism (EULAR) has produced recommendations for using imaging in rheumatoid arthritis (RA) management to aid diagnosis, assessment of prognosis, assessment of treatment response/disease activity and to support remission surveillance. ${ }^{1}$ How these recommendations should be applied, however, is open to interpretation.

Among the different imaging techniques, ultrasound (US) has shown to be of particular help in the diagnostic workup of RA, in guiding treatment decisions and in monitoring disease activity and remission. Despite the difference in the quality of the US machines ${ }^{2-4}$ and the possible different level of experience of the operators, published data support the value of using US in the management of patients with inflammatory arthritis. ${ }^{15}$ This evidence has encouraged many rheumatologists to embrace US in their clinical practice. ${ }^{6}$ The expansion of US in rheumatology has occurred alongside, and is complementary to, the acceptance of the treat-to-target model, in which disease activity and response to treatment must be closely monitored. ${ }^{7}$

The prompt diagnosis of RA and early initiation of disease-modifying antirheumatic drugs (DMARDs) reduce inflammation, limit disease progression, control symptoms and minimise functional loss. ${ }^{8-10}$ According to the American College of Rheumatology (ACR)/EULAR classification criteria, ${ }^{11}$ a patient with synovitis can be classified as having RA if a certain number of joints with synovitis are detected or if bone erosions are present. However, clinical examination and conventional radiography (CR) are neither sensitive nor accurate enough to detect disease activity and structural damage in early disease. ${ }^{12-15}$

In contrast, US is able to detect synovitis at presentation and differentiate between intra-joint synovial inflammation and other causes of symptoms/ swelling, such as tenosynovitis, bursitis and other soft tissue lesions. ${ }^{16-20}$ This is also reflected in the ACR/EULAR classification criteria, in which US-detected synovitis in clinically unaffected joints may be used to increase the number of involved joints to satisfy the fulfilment of the classification criteria. $^{21}$ Moreover, the earlier the patients are diagnosed and treated, the more likely they are to achieve remission and subsequently not flare if treatment is reduced. ${ }^{22}$

Once the presence of RA is confirmed, the optimal management requires tight therapeutic control for setting remission as primary treatment goal as stated by the EULAR recommendations for the management of RA. ${ }^{23}$ These recommendations underline that even patients with long-standing disease should be able to achieve stability with low disease activity (LDA). Therefore, an early, accurate assessment of treatment response/level of inflammation is essential. US offers objective information on how synovitis is responding to treatment which can be either the first DMARD in early RA or a change of therapy in more established disease. ${ }^{24} 25$ It can confirm a good response, identify a poor response and detect a loss of response.

The use of US to monitor patients considered to be in remission can help predict those likely to suffer subsequent joint damage and flare-up of disease. ${ }^{26}$ It has been shown that between $15 \%$ and $62 \%$ of patients considered to be in remission based on clinical examination have synovial hypertrophy on US. ${ }^{27-29}$

Between $19 \%$ and $30 \%$ of patients also have radiographic progression on further evaluation. ${ }^{30} \mathrm{It}$ has also been suggested that remission should only be defined in the absence of synovitis as shown by US. ${ }^{31}$

Although EULAR recommendations and published data support the use of US in several areas of RA management, they do not provide specific 
guidance on how to use US, which may result in an inconsistent or suboptimal utilisation of US and potentially the suboptimal treatment of patients. Therefore, there is a clear need for pragmatic, expert guidance for clinicians wishing to use US in their daily practice.

To address this need, a group of musculoskeletal US experts reviewed the available literature and discussed the best approach for developing pragmatic suggestions for the use of US in the daily management of patients with suspected or established RA.

The authors also reflected on the areas for which there is a paucity of evidence, by producing a research agenda for optimising the application of US in clinical practice.

\section{METHODS}

A two-step procedure was followed. The expert group, composed of 10 rheumatologists experienced in musculoskeletal US representing seven European countries (Denmark, England, France, Germany, Hungary, Italy and Spain), met twice in September 2014 and January 2015. The objectives of these meetings were: (1) to formulate key clinical questions related to the use of US in RA, (2) to identify and critically appraise the available evidence and (3) to generate pragmatic algorithms on the application of US in suspected or established RA based on both evidence and expert opinion. To meet the first and second objectives, the group was divided into three task forces: (1) diagnosis, (2) assessment of treatment response and (3) assessment of disease state. Each task force used the search terms of the systematic literature review (SLR) used for producing the EULAR imaging recommendations, ${ }^{1}$ which was proposed as online supplementary material for the published article. They, therefore, updated the literature search to January 2015 using the same MeSH (Medical Subject Headings) terms. Any paper published after this date was incorporated if relevant for the purpose of the project (narrative literature search). The articles were analysed from the perspective of three key questions: (1) the role of US for improving the diagnosis of RA, (2) the role of US for monitoring response to treatment and (3) the role of US in evaluating subclinical disease activity in stable disease. It was decided not to create a separate research question for addressing the specific role of US as a predictive tool for diagnosis, severity or response to treatment, as few data are available for supporting a separate question. However, prediction aspects have been investigated in each of the three above-mentioned research questions.

The results of the literature review were detailed and considered by the group to establish what is known (evidence) and what is unknown or uncertain (more evidence needed). In cases of uncertainty or lack of evidence, it was agreed that consensus expert opinion should guide the best use of US in these particular circumstances and future research questions should be developed to reduce uncertainty. A $100 \%$ agreement (ie, unanimous) was required in case of lack of literature evidence. Five algorithms were finalised according to this process (figures 1-5).

\section{RESULTS AND DISCUSSION}

\section{Using US to establish or confirm a diagnosis of RA}

Since 2010, new classification criteria, the ACR/EULAR 2010 criteria, has been proposed for helping to classify patients suffering from RA at an earlier stage of disease than by using the modified ACR 1987 criteria. $^{11}$ This means that patients can benefit from an appropriate treatment before the structural damage lesions detected by CR appear.

However, some studies have supported the fact that even these new criteria can lack both sensitivity (ie, delaying diagnosis) and specificity (ie, overestimating the presence of true RA). ${ }^{32-37}$

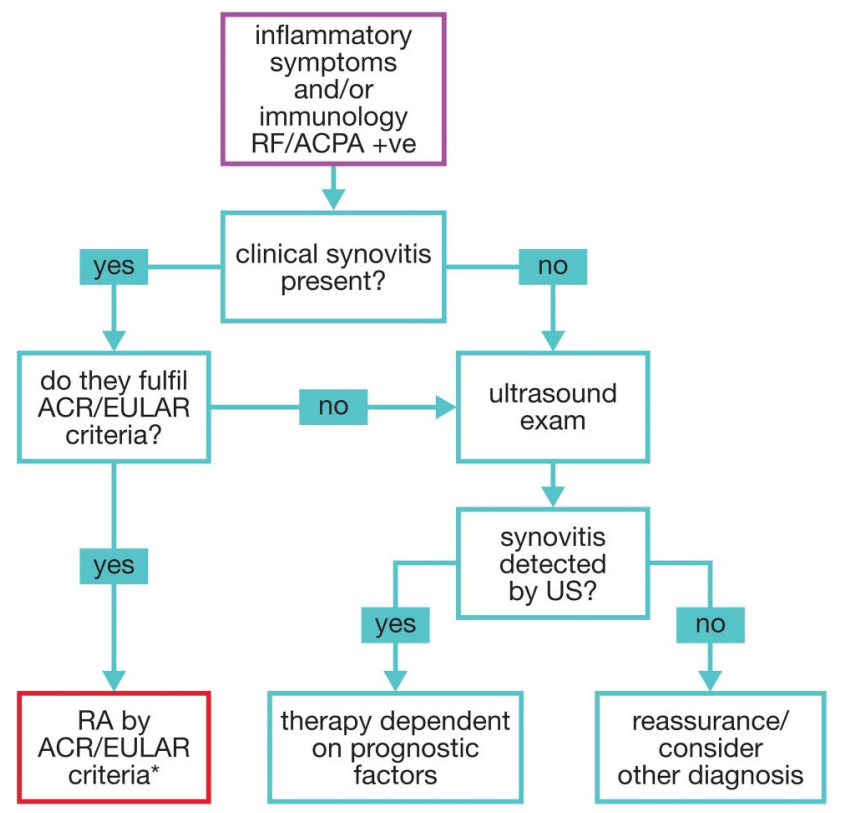

*See algorithm 2 for further details

Figure 1 Flow chart showing the ultrasound (US) evaluation in patients at risk of rheumatoid arthritis (RA) or suspected RA. Purple rectangle denotes population of interest (or starting point); blue-green rectangles denote possible paths of the algorithm and red rectangle denotes final diagnosis. ACPA, anti-citrullinated peptide antibody; ACR, American College of Rheumatology; EULAR, European League against Rheumatism; RF, rheumatoid factor.

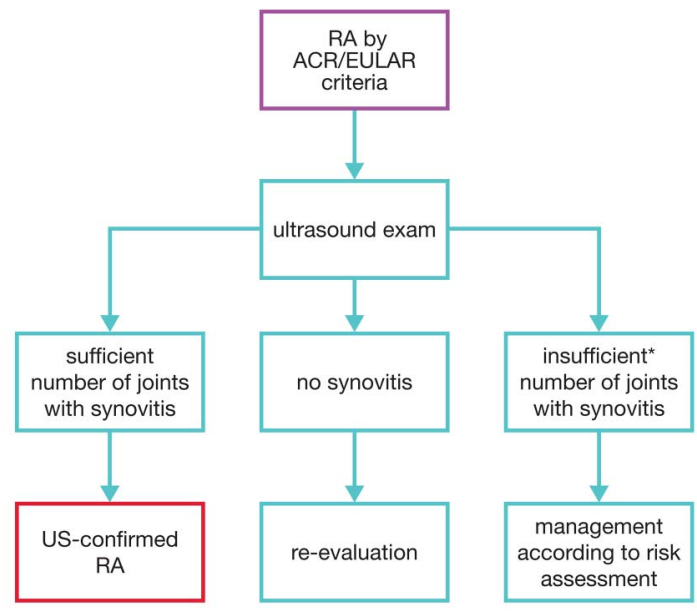

*Insufficient number of joints with synovitis = too few to satisfy ACR/EULAR criteria

Figure 2 Flow chart showing the ultrasound (US) evaluation in patients who fulfil American College of Rheumatology (ACR)/European League against Rheumatism (EULAR) criteria. Purple rectangle denotes population of interest (or starting point); blue-green rectangles denote possible paths of the algorithm and red rectangle denotes final diagnosis.

There is substantial evidence to show that US supports a more accurate and sensitive diagnosis of RA than both clinical assessment and CR. ${ }^{12-14}$ According to EULAR imaging recommendations, the detection rate of synovitis at the hand and wrist using US was double than that obtained with clinical examination. ${ }^{1}$

Patients assessed by US are likely to fulfil the ACR/EULAR criteria for RA at an earlier stage of their disease than those assessed using conventional assessment. ${ }^{7} 323839$ 
Figure 3 Flow chart showing the ultrasound (US) evaluation of therapeutic response in patients with rheumatoid arthritis (RA) starting csDMARDs or bDMARDs. Purple rectangle denotes population of interest (or starting point); red text denotes CSDMARDs; blue text denotes bDMARDs; blue-green rectangles denote possible paths of the algorithm; red rectangle denotes proposed path for csDMARDs population and blue rectangle denotes proposed path for bDMARDs. bDMARDs, biological disease-modifying antirheumatic drugs; csDMARDs, conventional synthetic disease-modifying antirheumatic drugs; TNFi, tumour necrosis factor inhibitor.

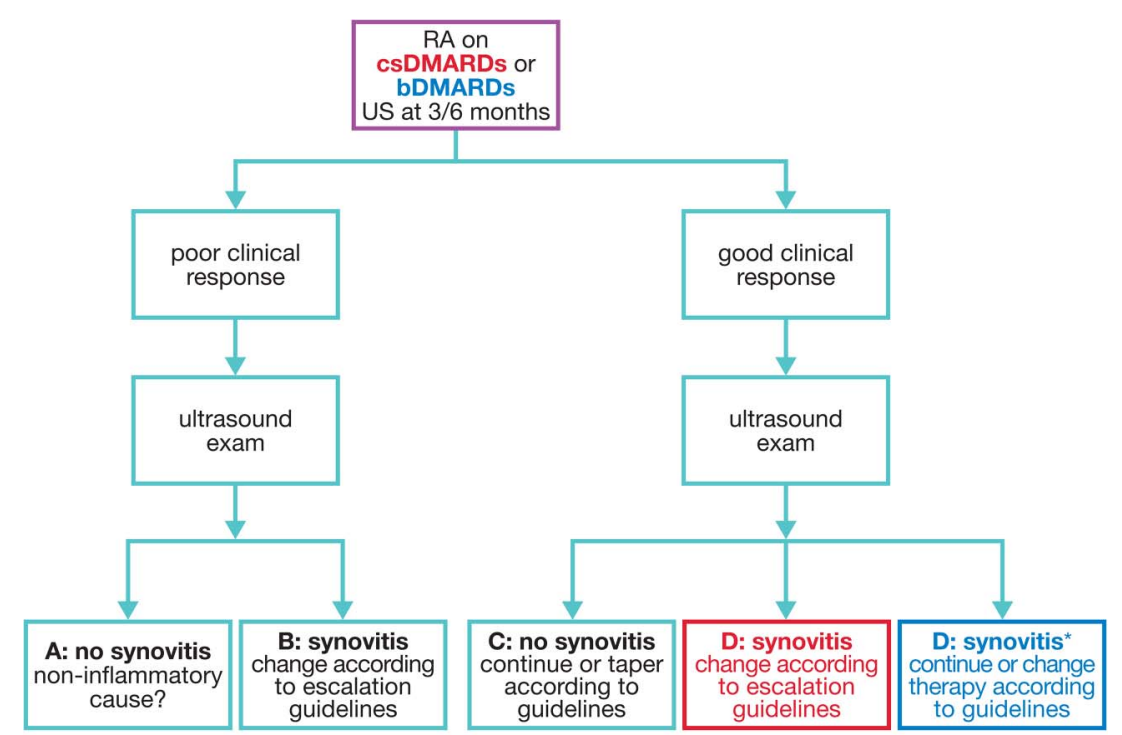

*Value of US uncertain as synovitis/PD poor predictor of damage on TNFi
In addition, US may be particularly useful for the differential diagnosis of RA, as it can differentiate between joint inflammation and tenosynovitis, bursitis and other soft tissue lesions that can mimic clinical synovitis. ${ }^{19} 20$

Recent data suggest that Doppler US can detect subclinical RA in at-risk patients who are seropositive (for rheumatoid factor or anti-citrullinated peptide antibodies (ACPAs)) but who have not yet developed clinical signs of inflammation. ${ }^{40}{ }^{41}$ Both the qualitative and quantitative features of this subclinical inflammation have been shown, in seronegative patients, to predict future clinical progression to RA. ${ }^{42}$ The value of adding US to routine assessment seems to be greatest in ACPA-negative patients. $^{42}$

The experts, therefore, proposed three potential uses of US during the diagnostic workup, and in the absence of definite

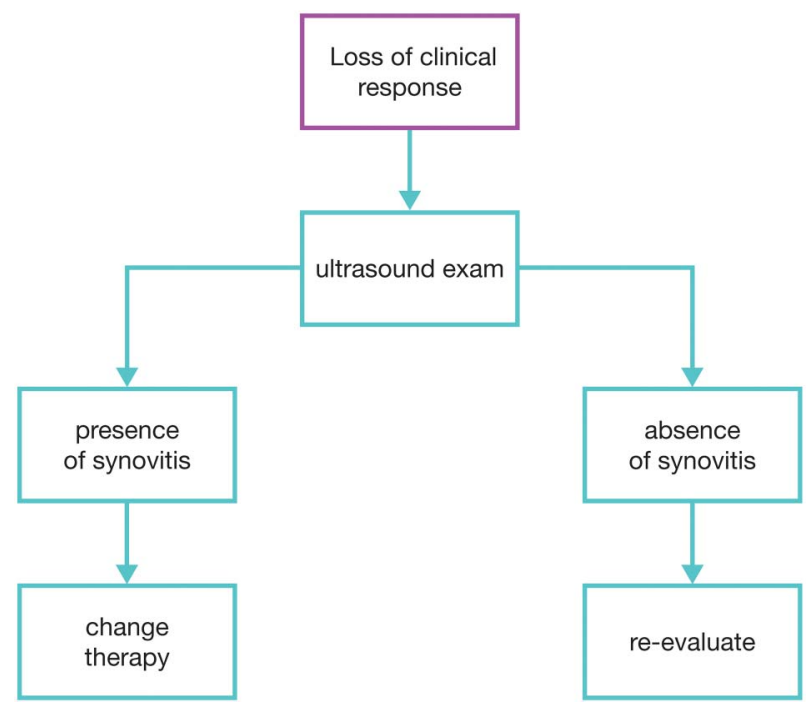

Figure 4 Flow chart showing the ultrasound evaluation in patients with rheumatoid arthritis with loss of treatment response (both conventional synthetic or biological disease-modifying anti-rheumatic drugs). Purple rectangle denotes population of interest (or starting point) and blue-green rectangles denote possible paths of the algorithm. erosions at CR: (1) to determine whether subclinical synovitis is present in at-risk patients with no sign of inflammation on clinical examination; (2) to reassess patients whose clinical synovitis does not fulfil ACR/EULAR criteria and (3) to confirm the diagnosis in patients who fulfil the ACR/EULAR criteria on clinical examination, but for whom there is a doubt to be considered as 'false-positive' or where synovitis is the outcome (eg, on entry to a study).

Figures 1 and 2 summarise these proposals. In figure 1 , it is suggested that patients considered at risk of RA due to symptoms and/or seropositivity or with clinically suspected RA should undergo an US evaluation along with a full clinical examination, including CR. This additional evaluation could improve patient outcome by facilitating the application of ACR/ EULAR criteria, either by increasing the number of inflamed joints or, in absence of clinically detected inflammation, by confirming the presence of subclinical synovitis, allowing, therefore,

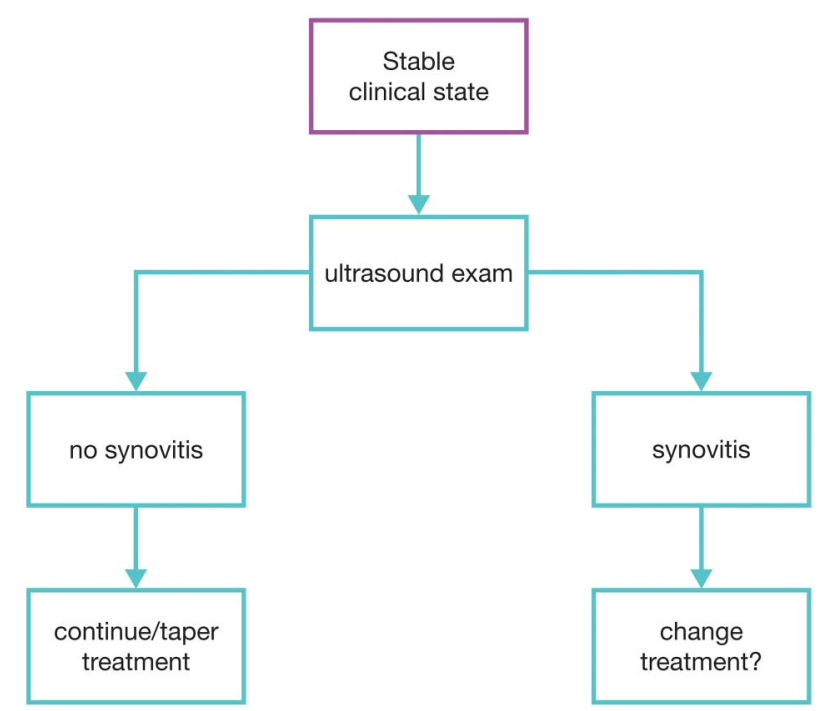

Figure 5 Flow chart showing the ultrasound evaluation in assessing remission or low disease activity in patients with rheumatoid arthritis. Purple rectangle denotes population of interest (or starting point) and blue-green rectangles denote possible paths of the algorithm. 
a diagnosis at an earlier stage. US may also be helpful in excluding the presence of RA in case of normality of the US evaluation. In the latter cases, therapeutic management will be adapted according to the presence of concomitant prognostic factors.

Additionally, an US examination even in patients fulfilling ACR/EULAR criteria (figure 2) at baseline evaluation has been proposed. The use of US in those patients may help to detect false-positive patients by excluding other causes of joint pathology such as inflammatory flare of osteoarthritis or crystalrelated diseases, based on the US appearance of typical findings (ie, osteophytes, crystals, presence of double contour, etc). It is still a matter of debate as to how to determine the true ability of US to exclude diseases other than RA. There is some evidence to recommend specific cut-off values for greyscale (GS) and Doppler US to confirm the presence of inflammation at joint level for the diagnosis of RA. ${ }^{38} 43$ Increasing cut-off thresholds has been shown to increase the specificity for RA but at the expense of decreased sensitivity. ${ }^{32}$

\section{Research agenda}

- Threshold of normality of US findings

- Minimal number of joints to scan for diagnostic purposes

- Predictive validity of subclinical, US-detected synovitis in terms of 'window of opportunity'

\section{Using US in assessing response to treatment}

Published data have consistently shown that US can detect a response in US-detected joint inflammation after treatment (for between 1 week and 1 year) in patients treated with either conventional synthetic DMARDs (csDMARDs) or biological DMARDs (bDMARDs). ${ }^{15}$ 44-60 Both GS and Doppler are at least as sensitive as clinical examination and laboratory markers in detecting changes in patients with RA who have initiated effective therapy. ${ }^{60}$ The more comprehensive the US examination, the more sensitive it is in detecting change. ${ }^{51}$ However, reduced-joint US assessments have also shown a good sensitivity, ${ }^{4748556061}$ focusing either on a few target joints such as the wrist, metacarpophalangeal and metatarsophalangeal joints or on a few small joints plus one or two large joints. ${ }^{47} 48556062$

Based on the literature review and experts' opinion, it is proposed that patients with RA on either csDMARDs or bDMARDs should undergo assessment with US at baseline treatment and after 3-6 months of treatment to assess initial response, in order to help clinicians tailor therapy (maintaining, changing or tapering). Figures 3 and 4 summarise the pragmatic algorithms for using US in assessing treatment response either under csDMARDs or bDMARDs.

Figure 3 shows the proposed use of US in patients with RA on csDMARDs or bDMARDs to (1) re-evaluate noninflammatory causes of poor clinical response in patients without US synovitis (A) (2) support change of treatment (ie, escalation) in patients with poor clinical response and confirmed US synovitis (B), (3) maintain or taper the dosage in patients with good clinical response and absence of US synovitis (C) and, finally, (4) assess change of therapy (ie, escalation) in patients on csDMARDs with good clinical response but significant US synovitis (D) or in case of patients on bDMARDs to possibly maintain the therapy, as the importance of synovitis in patients on a bDMARD is less certain.

Finally, figure 4 shows the suggested use of US to support change of treatment versus investigation of non-inflammatory causes in patients with loss of clinical response with US synovitis or without US synovitis, respectively, independently of the treatment (csDMARDs and/or bDMARDs). In particular, in such patients with a good clinical response, the presence of US synovitis would make tapering of treatment inadvisable. ${ }^{63}$

Detection of synovitis is important since Doppler, as well as GS, US-detected synovitis is able to predict structural damage in both early $\mathrm{RA}^{31} 41^{64-68}$ and in established disease. ${ }^{69}{ }^{70}$ The importance of synovitis in patients on a bDMARD needs further investigation.

Some data suggest that US-detected bone erosions may also be sensitive to change. ${ }^{59} 71$

By evaluating the real presence of inflammation and by excluding other causes of joint pain (such as joint deformity or periarticular lesions) the use of US in assessing response to therapy can be of a great help in clinical practice. The same consideration expressed in the previous section on diagnosis and the capability of US to discriminate different diseases is also of debate in this context. In addition, recent studies question the benefit of US for managing patients with early RA for reaching a therapeutic target (such as LDA) according to disease activity score (DAS) values. ${ }^{24} 2533$ In fact, in these two randomised, controlled studies, the 'target control', based on US data, did not do better than the target control based on DAS 28, either for DAS response over time or for radiographic progression. However, it is worth noting that in both studies the achievement of a DAS remission was higher in the US group. Further studies, with a higher number of patients, in an international multicentre setting, on patients with RA having different disease duration and different disease activity (and with different endpoints/outcomes) are needed for confirming or refuting these results.

\section{Research agenda}

- Is Doppler alone sufficient to monitor response to therapy?

- Should the same US mode (GS versus Doppler, or both combined) be applied in early and established disease?

- Which reduced joint assessments are most sensitive to change in early and established RA?

- Should tenosynovitis be included in the US evaluation of RA?

- How often should US be used to monitor therapeutic response?

- What is the long-term impact on RA outcomes of US evaluation?

- Should a strategy trial be performed only in international multicentre settings?

\section{US in assessing remission/LDA state}

Sustained remission is important as flares predict erosive progression over time and functional disability. ${ }^{72-74}$ Studies have shown that in patients in remission determined either by physician or by use of various remission criteria, subclinical synovitis is present in both GS and Doppler ${ }^{27-29}$ and that the amount of synovitis detected by US is independent of whether the patient is receiving csDMARDs or bDMARDs. ${ }^{75}$ Studies of patients on csDMARD therapy have shown that a Doppler signal of $>1$ is associated with erosive progression on X-ray over time ${ }^{76}$ and synovitis shown by GS US indicate the occurrence or worsening of bone erosions. ${ }^{30}$

The presence of subclinical synovitis with a Doppler signal of $>1$ increases the risk of disease flare up in patients with RA in remission $^{26} 3177$ whereas having Doppler-negative joints is the best predictor for not experiencing a flare. ${ }^{31}$ The need to taper or stop bDMARD treatment should also be carried out so flares are avoided. Patients with a high US score on GS and Doppler 
are more likely to relapse when stopping or tapering biological therapy than patients with a low score. ${ }^{6378}$

Based on the literature review and experts' opinion, patients with RA on both csDMARDs and bDMARDs should undergo assessment with US. The best time decided by the expert is at least after 6 months of clinical stable disease state to determine possible need for treatment alterations (increased or tapered).

Figure 5 shows the proposed algorithm for using US in patients on both csDMARDs and bDMARDs who are in stable clinical state. If the US examination does not reveal signs of synovitis, then either the current treatment must be continued or the tapering of the treatment must be considered. If the US examination reveals synovitis, change or optimisation of the current treatment must be considered.

\section{Research agenda}

- Define the threshold of US remission according to the duration of the disease

- Explore if all treated patients with RA achieve US-defined remission

- Does achieving US-defined remission improve patient outcomes?

- How frequently should US be used to confirm absence of disease activity in patients in US-defined remission?

\section{CONCLUSION}

Developments in the management of RA in recent years have produced remarkable improvements in patient outcomes to the point where almost every patient now has a realistic chance of achieving either remission or LDA. It is important that imaging techniques keep pace with these advancements. While clinical assessment and CR have shown considerable value in the diagnosis and monitoring of RA, used alone they do not have sufficient sensitivity to support the current treat-to-target approach. The addition of targeted US assessment will help improve diagnosis and treatment of patients with RA in daily clinical practice and the algorithmic approach presented in this paper might help to achieve this goal. In this context, the availability of highquality machines with a Doppler setting adapted to the study of slow flow as observed in inflammatory tissues will permit greater homogeneity of US reports and an easier and wider utilisation of US in clinical daily management. In this context, educational and training tools play a key role in improving the skills of rheumatologists in US as well as in teaching its pragmatic use in clinical practice. ${ }^{79}$

The optimal dissemination and application of the proposed algorithmic approaches for using US in the management of patients with new and established RA will require the support of educational initiatives and training activities. Further multicentre studies are needed for evaluating the implementation of these pragmatic approaches on patient outcomes, for evaluating the feasibility of an US approach and for evaluating the costeffectiveness, as compared with standard of care.

\section{Author affiliations}

${ }^{1}$ Rheumatology Department, APHP, Hôpital Ambroise Paré, Boulogne-Billancourt, France

${ }^{2}$ INSERM U1173, Laboratoire d'Excellence INFLAMEX, UFR Simone Veil, VersaillesSaint-Quentin University, Saint-Quentin en Yvelines, France

${ }^{3}$ Leeds Institute of Rheumatic and Musculoskeletal Medicine, University of Leeds, Chapel Allerton Hospital, Leeds, UK

${ }^{4}$ Copenhagen Center for Arthritis Research, Center for Rheumatology and Spine Diseases, Rigshospitalet, Glostrup, Denmark

${ }^{5}$ Department of Clinical Medicine, University of Copenhagen, Copenhagen, Denmark ${ }^{6}$ NIHR Leeds Musculoskeletal Biomedical Research Unit, Leeds Teaching Hospitals NHS Trust, Leeds, UK
${ }^{7}$ Third Rheumatology Department, National Institute of Rheumatology and Physiotherapy, Budapest, Hungary

${ }^{8}$ Department of Rheumatology, Hospital General Universitario Gregorio Marañón and Universidad Complutense, Madrid, Spain

${ }^{9}$ Ultrasound Unit, Rheumatology Department, Sapienza Università di Roma, Rome, Italy

${ }^{10}$ Department of Internal Medicine, Rheumatology and Clinical Immunology Academic Hospital of the Charité Berlin, Park-Klinik Weissensee Berlin, Berlin, Germany

${ }^{11}$ Clinica Reumatologica-Scuola di Specializzazione in Reumatologia Università Politecnica delle Marche, Ancona, Italy

Contributors MADA and PE substantially contributed to the conception and design of the work, the acquisition, analysis and interpretation of data, drafting the work and revising it critically for important intellectual content. LT, RW, MØ, EN, Al, WG contributed to the analysis and interpretation of data, drafting the work and revising it critically for important intellectual content. Final approval of the version published was done by all authors.

Funding AbbVie provided an independent grant to the University of Leeds to support the development of this paper. Medical writing and meeting organisation was provided by Patient Central. The authors of this paper are members of the independent TUI Steering Committee, which has previously received support from AbbVie.

Competing interests $\mathrm{PE}$ has undertaken clinical trials and provided expert advice to Pfizer, MSD, Abbvie, BMS, UCB, Roche, Novartis, Samsung, Sandoz and Lilly. MADA has received speaker bureau from MSD, Abbvie, BMS, UCB, Roche and Novartis.

Provenance and peer review Not commissioned; externally peer reviewed.

\section{REFERENCES}

1 Colebatch AN, Edwards CJ, Østergaard M, et al. EULAR recommendations for the use of imaging of the joints in the clinical management of rheumatoid arthritis. Ann Rheum Dis 2013;72:804-14.

2 Zayat AS, Freeston JE, Conaghan PG, et al. Does joint position affect US findings in inflammatory arthritis? Rheumatology (Oxford) 2012;51:921-5.

3 Torp-Pedersen S, Christensen R, Szkudlarek M, et al. Power and color Doppler ultrasound settings for inflammatory flow: impact on scoring of disease activity in patients with rheumatoid arthritis. Rheumatology (Oxford) 2015;67:386-95.

4 Terslev L, Hammer HB, Torp-Pedersen S, et al. EFSUMB minimum training requirements for rheumatologists performing musculoskeletal ultrasound. Ultraschall Med 2013;34:475-7.

5 Mandl P, Naredo E, Wakefield RJ, et al. A systematic literature review analysis of ultrasound joint count and scoring systems to assess synovitis in rheumatoid arthritis according to the OMERACT filter. J Rheumatol 2011;38:2055-62.

6 Rowbotham EL, Wakefield RJ, Grainger AJ. The technique and application of ultrasound in the diagnosis and management of inflammatory arthritis. Semin Musculoskelet Radiol 2012;16:360-6.

7 Smolen JS, Aletaha D, Bijlsma JW, et al. Treating rheumatoid arthritis to target: recommendations of an international task force. Ann Rheum Dis 2010;69:631-7.

8 Goekoop-Ruiterman YP, de Vries-Bouwstra JK, Allaart CF, et al. Clinical and radiographic outcomes of four different treatment strategies in patients with early rheumatoid arthritis (the BeSt study): a randomized, controlled trial. Arthritis Rheum 2008;58(2 Suppl):S126-35.

9 Nell VP, Machold KP, Eberl G, et al. Benefit of very early referral and very early therapy with disease-modifying anti-rheumatic drugs in patients with early rheumatoid arthritis. Rheumatology (Oxford) 2004;43:906-14.

10 Finckh $\mathrm{A}$, Liang $\mathrm{MH}$, van Herckenrode $\mathrm{CM}$, et al. Long-term impact of early treatment on radiographic progression in rheumatoid arthritis: a meta-analysis. Arthritis Rheum 2006;55:864-72.

11 Aletaha D, Neogi T, Silman AJ, et al. 2010 Rheumatoid arthritis classification criteria: an American College of Rheumatology/European League Against Rheumatism collaborative initiative. Ann Rheum Dis 2010;69:1580-8.

12 Joshua F, Edmonds J, Lassere M. Power Doppler ultrasound in musculoskeletal disease: a systematic review. Semin Arthritis Rheum 2006:36:99-108.

13 Wakefield RJ, Gibbon WW, Conaghan PG, et al. The value of sonography in the detection of bone erosions in patients with rheumatoid arthritis: a comparison with conventional radiography. Arthritis Rheum 2000;43:2762-70.

14 Grassi W, Filippucci E, Farina A, et al. Ultrasonography in the evaluation of bone erosions. Ann Rheum Dis 2001;60:98-103.

15 Saraux A, Berthelot JM, Chalès G, et al. Ability of the American College of Rheumatology 1987 criteria to predict rheumatoid arthritis in patients with early arthritis and classification of these patients two years later. Arthritis Rheum 2001:44:2485-91.

16 Wakefield RJ, D'Agostino MA, lagnocco A, et al. The OMERACT Ultrasound Group: status of current activities and research directions. J Rheumatol 2007;34:848-51. 
17 Yoshimi R, Hama M, Takase K, et al. Ultrasonography is a potent tool for the prediction of progressive joint destruction during clinical remission of rheumatoid arthritis. Mod Rheumatol 2013;23:456-65.

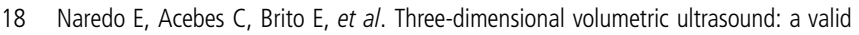
method for blinded assessment of response to therapy in rheumatoid arthritis. J Rheumatol 2013;40:253-60.

19 Alcalde M, D'Agostino MA, Bruyn GA, et al. A systematic literature review of US definitions, scoring systems and validity according to the OMERACT filter for tendon lesion in RA and other inflammatory joint diseases. Rheumatology (Oxford) 2012;51:1246-60.

20 Ziswiler HR, Tamborrini G. [Musculoskeletal ultrasound II - "why are bats better than physicians"]. Praxis (Bern 1994) 2011;100:1297-302.

21 Østergaard M. Clarification of the role of ultrasonography, magnetic resonance imaging and conventional radiography in the ACR/EULAR 2010 rheumatoid arthritis classification criteria-comment to the article by Aletaha et al. Ann Rheum Dis Published Online First: 2 Dec 2010.

22 Saleem B, Keen H, Goeb V, et al. Patients with RA in remission on TNF blockers: when and in whom can TNF blocker therapy be stopped? Ann Rheum Dis 2010;69:1636-42.

23 Smolen JS, Landewé R, Breedveld FC, et al. EULAR recommendations for the management of rheumatoid arthritis with synthetic and biological disease-modifying antirheumatic drugs: 2013 update. Ann Rheum Dis 2014;73:492-509.

24 Dale J, Purves D, McConnachie A, et al. Tightening up? Impact of musculoskeletal ultrasound disease activity assessment on early rheumatoid arthritis patients treated using a treat to target strategy. Arthritis Care Res (Hoboken) 2014;66:19-26.

25 Dale J, Stirling A, Zhang R, et al. Targeting ultrasound remission in early rheumatoid arthritis: the results of the TaSER study, a randomised clinical trial. Ann Rheum Dis 2016;75:1043-50.

26 Saleem B, Brown AK, Quinn M, et al. Can flare be predicted in DMARD treated RA patients in remission, and is it important? A cohort study. Ann Rheum Dis 2012;71:1316-21.

27 Saleem B, Brown AK, Keen H, et al. Should imaging be a component of rheumatoid arthritis remission criteria? A comparison between traditional and modified composite remission scores and imaging assessments. Ann Rheum Dis 2011;70:792-8.

28 Ozgocmen S, Ozdemir H, Kiris A, et al. Clinical evaluation and power Doppler sonography in rheumatoid arthritis: evidence for ongoing synovial inflammation in clinical remission. South Med J 2008;101:240-5.

29 Brown AK, Quinn MA, Karim Z, et al. Presence of significant synovitis in rheumatoid arthritis patients with disease-modifying antirheumatic drug-induced clinical remission: evidence from an imaging study may explain structural progression. Arthritis Rheum 2006;54:3761-73.

30 Lillegraven S, Prince FH, Shadick NA, et al. Remission and radiographic outcome in rheumatoid arthritis: application of the 2011 ACR/EULAR remission criteria in an observational cohort. Ann Rheum Dis 2012;71:681-6.

31 Foltz V, Gandjbakhch F, Etchepare F, et al. Power Doppler ultrasound, but not low-field magnetic resonance imaging, predicts relapse and radiographic disease progression in rheumatoid arthritis patients with low levels of disease activity. Arthritis Rheum 2012;64:67-76.

32 Nakagomi D, Ikeda K, Okubo A, et al. Ultrasound can improve the accuracy of the 2010 American College of Rheumatology/European League against rheumatism classification criteria for rheumatoid arthritis to predict the requirement for methotrexate treatment. Arthritis Rheum 2013:65:890-8.

33 Haavardsholm EA, Aga A-B, Olsen IC, et al. Ultrasound in the management of rheumatoid arthritis: ARCTIC randomised controlled strategy trial. BMJ 2016;354: i4205

34 Płaza M, Nowakowska-Płaza A, Pracoń G, et al. Role of ultrasonography in the diagnosis of rheumatic diseases in light of ACR/EULAR guidelines. J Ultrason 2016;16:55-64.

35 Le Loët $X$, Nicolau J, Boumier $P$, et al. Validation of the 2010-ACR/EULAR -classification criteria using newly EULAR-defined erosion for rheumatoid arthritis on the very early arthritis community-based (VErA) cohort. Joint Bone Spine 2015:82:38-41.

36 van der Ven M, Alves C, Luime JJ, et al. Do we need to lower the cut point of the 2010 ACR/EULAR classification criteria for diagnosing rheumatoid arthritis? Rheumatology (Oxford) 2016;55:636-9.

37 Luime JJ, Buisman LR, Oppe M, et al. Cost-effectiveness model for evaluating new diagnostic tests in the evaluation of patients with inflammatory arthritis at risk of having rheumatoid arthritis. Arthritis Care Res (Hoboken) 2016;68:927-35.

38 Filer $A$, de Pablo P, Allen $G$, et al. Utility of ultrasound joint counts in the prediction of rheumatoid arthritis in patients with very early synovitis. Ann Rheum Dis 2011:70:500-7.

39 Wakefield RJ, Green MJ, Marzo-Ortega H, et al. Should oligoarthritis be reclassified? Ultrasound reveals a high prevalence of subclinical disease. Ann Rheum Dis 2004;63:382-5.

40 Rakieh C, Nam JL, Hunt L, et al. Predicting the development of clinical arthritis in anti-CCP positive individuals with non-specific musculoskeletal symptoms: a prospective observational cohort study. Ann Rheum Dis 2015;74:1659-66.
41 Nam JL, Hensor EM, Hunt L, et al. Ultrasound findings predict progression to inflammatory arthritis in anti-CCP antibody-positive patients without clinical synovitis. Ann Rheum Dis Published Online First: 22 Jan 2016. doi: 10.1136/ annrheumdis-2015-208235.

42 Freeston JE, Wakefield RJ, Conaghan PG, et al. A diagnostic algorithm for persistence of very early inflammatory arthritis: the utility of power Doppler ultrasound when added to conventional assessment tools. Ann Rheum Dis 2010;69:417-19.

43 Padovano I, Costantino F, Breban M, et al. Prevalence of ultrasound synovial inflammatory findings in healthy subjects. Ann Rheum Dis 2016;75:1819-23.

44 Terslev L, Torp-Pedersen S, Qvistgaard E, et al. Effects of treatment with etanercept (Enbrel, TNRF:Fc) on rheumatoid arthritis evaluated by Doppler ultrasonography. Ann Rheum Dis 2003:62:178-81.

45 lagnocco A, Filippucci $E$, Meenagh $G$, et al. Ultrasound imaging for the rheumatologist III. Ultrasonography of the hip. Clin Exp Rheumatol 2006;24:229-32

46 Albrecht K, Grob K, Lange U, et al. Reliability of different Doppler ultrasound quantification methods and devices in the assessment of therapeutic response in arthritis. Rheumatology (Oxford) 2008;47:1521-6.

47 Naredo E, Rodríguez M, Campos C, et al. Validity, reproducibility, and responsiveness of a twelve-joint simplified power Doppler ultrasonographic assessment of joint inflammation in rheumatoid arthritis. Arthritis Rheum 2008:59:515-22

48 Backhaus M, Ohrndorf S, Kellner H, et al. Evaluation of a novel 7-joint ultrasound score in daily rheumatologic practice: a pilot project. Arthritis Rheum 2009;61:1194-201.

49 Haavardsholm EA, Østergaard M, Hammer HB, et al. Monitoring anti-TNFalpha treatment in rheumatoid arthritis: responsiveness of magnetic resonance imaging and ultrasonography of the dominant wrist joint compared with conventional measures of disease activity and structural damage. Ann Rheum Dis 2009;68:1572-9.

50 Dougados M, Jousse-Joulin S, Mistretta F, et al. Evaluation of several ultrasonography scoring systems for synovitis and comparison to clinical examination: results from a prospective multicentre study of rheumatoid arthritis. Ann Rheum Dis 2010:69:828-33.

51 Hammer HB, Sveinsson M, Kongtorp AK, et al. A 78-joints ultrasonographic assessment is associated with clinical assessments and is highly responsive to improvement in a longitudinal study of patients with rheumatoid arthritis starting adalimumab treatment. Ann Rheum Dis 2010;69:1349-51.

52 Larché MJ, Seymour M, Lim A, et al. Quantitative power Doppler ultrasonography is a sensitive measure of metacarpophalangeal joint synovial vascularity in rheumatoid arthritis and declines significantly following a 2-week course of oral low-dose corticosteroids. J Rheumatol 2010;37:2493-501.

53 Hammer HB, Bolton-King P, Bakkeheim V, et al. Examination of intra and interrater reliability with a new ultrasonographic reference Atlas for scoring of synovitis in patients with rheumatoid arthritis. Ann Rheum Dis 2011;70:1995-8.

54 Døhn UM, Ejbjerg B, Boonen A, et al. No overall progression and occasional repair of erosions despite persistent inflammation in adalimumab-treated rheumatoid arthritis patients: results from a longitudinal comparative MRI, ultrasonography, CT and radiography study. Ann Rheum Dis 2011;70:252-8.

55 Perricone C, Ceccarelli F, Modesti M, et al. The 6-joint ultrasonographic assessment: a valid, sensitive-to-change and feasible method for evaluating joint inflammation in RA. Rheumatology (Oxford) 2012;51:866-73.

56 Damjanov N, Radunovic G, Prodanovic $S$, et al. Construct validity and reliability of ultrasound disease activity score in assessing joint inflammation in RA: comparison with DAS-28. Rheumatology (Oxford) 2012;51:120-8.

57 Seymour M, Pétavy F, Chiesa F, et al. Ultrasonographic measures of synovitis in an early phase clinical trial: a double-blind, randomised, placebo and comparator controlled phase lla trial of GW274150 (a selective inducible nitric oxide synthase inhibitor) in rheumatoid arthritis. Clin Exp Rheumatol 2012;30:254-61.

58 Mandl P, Balint PV, Brault Y, et al. Clinical and ultrasound-based composite disease activity indices in rheumatoid arthritis: results from a multicenter, randomized study. Arthritis Care Res 2013;65:879-87.

59 Ohrndorf S, Messerschmidt J, Reiche BE, et al. Evaluation of a new erosion score by musculoskeletal ultrasound in patients with rheumatoid arthritis: is US ready for a new erosion score? Clin Rheumatol 2014;33:1255-62.

60 D'Agostino MA, Wakefield RJ, Berner-Hammer $\mathrm{H}$, et al. Value of ultrasonography as a marker of early response to abatacept in patients with rheumatoid arthritis and an inadequate response to methotrexate: results from the APPRAISE study. Ann Rheum Dis 2016;75:1763-9.

61 Mandl P, Balint PV, Brault Y, et al. Metrologic properties of ultrasound versus clinical evaluation of synovitis in rheumatoid arthritis: results of a multicenter, randomized study. Arthritis Rheum 2012;64:1272-82.

62 Aga $A B$, Hammer $H B$, Olsen IC, et al. First step in the development of an ultrasound joint inflammation score for rheumatoid arthritis using a data-driven approach. Ann Rheum Dis 2016;75:1444-51.

63 Naredo E, Valor L, De la Torre I, et al. Predictive value of Doppler ultrasound-detected synovitis in relation to failed tapering of biologic therapy in patients with rheumatoid arthritis. Rheumatology (Oxford) 2015;54: 1408-14. 


\section{Viewpoint}

64 Taylor PC, Steuer A, Gruber J, et al. Comparison of ultrasonographic assessment of synovitis and joint vascularity with radiographic evaluation in a randomized, placebo-controlled study of infliximab therapy in early rheumatoid arthritis. Arthritis Rheum 2004;50:1107-16.

65 Naredo E, Möller I, Cruz A, et al. Power Doppler ultrasonographic monitoring of response to anti-tumor necrosis factor therapy in patients with rheumatoid arthritis. Arthritis Rheum 2008;58:2248-56.

66 Bøyesen P, Haavardsholm EA, van der Heijde D, et al. Prediction of MRI erosive progression: a comparison of modern imaging modalities in early rheumatoid arthritis patients. Ann Rheum Dis 2011;70:176-9.

67 Fukae J, Kon Y, Henmi M, et al. Change of synovial vascularity in a single finger joint assessed by power Doppler sonography correlated with radiographic change in rheumatoid arthritis: comparative study of a novel quantitative score with a semiquantitative score. Arthritis Care Res 2010;62:657-63.

68 Funck-Brentano T, Gandjbakhch F, Etchepare F, et al. Prediction of radiographic damage in early arthritis by sonographic erosions and power Doppler signal: a longitudinal observational study. Arthritis Care Res 2013;65:896-902.

69 Dougados M, Devauchelle-Pensec V, Ferlet JF, et al. The ability of synovitis to predict structural damage in rheumatoid arthritis: a comparative study between clinical examination and ultrasound. Ann Rheum Dis 2013;72:665-71.

70 Macchioni $\mathrm{P}$, Magnani M, Mulè R, et al. Ultrasonographic predictors for the development of joint damage in rheumatoid arthritis patients: a single joint prospective study. Clin Exp Rheumatol 2013;31:8-17.

71 Naredo E, Valor L, De la Torre I, et al. Ultrasound joint inflammation in rheumatoid arthritis in clinical remission: how many and which joints should be assessed? Arthritis Care Res 2013;65:512-17.
72 Aletaha $\mathrm{D}$, Ward MM, Machold KP, et al. Remission and active disease in rheumatoid arthritis: defining criteria for disease activity states. Arthritis Rheum 2005;52:2625-36.

73 Molenaar ETH, Voskuyl AE, Dinant HJ, et al. Progression of radiologic damage in patients with rheumatoid arthritis in clinical remission. Arthritis Rheum 2004;50:36-42.

74 Markusse IM, Dirven L, Gerards AH, et al. Disease flares in rheumatoid arthritis are associated with joint damage progression and disability: 10-year results from the BeSt study. Arthritis Res Ther 2015;17:232.

75 Saleem B, Brown AK, Keen $\mathrm{H}$, et al. Disease remission state in patients treated with the combination of tumor necrosis factor blockade and methotrexate or with disease-modifying antirheumatic drugs: a clinical and imaging comparative study. Arthritis Rheum 2009;60:1915-22.

76 Brown AK, Conaghan PG, Karim Z, et al. An explanation for the apparent dissociation between clinical remission and continued structural deterioration in rheumatoid arthritis. Arthritis Rheum 2008;58:2958-67.

77 Scirè CA, Montecucco C, Codullo V, et al. Ultrasonographic evaluation of joint involvement in early rheumatoid arthritis in clinical remission: power Doppler signal predicts short-term relapse. Rheumatology 2009;48:1092-7.

78 Iwamoto T, Ikeda K, Hosokawa J, et al. Prediction of relapse after discontinuation of biologic agents by ultrasonographic assessment in patients with rheumatoid arthritis in clinical remission: high predictive values of total gray-scale and power Doppler scores that represent residual synovial inflammation before discontinuation. Arthritis Care Res 2014;66:1576-81.

79 Naredo E, Bijlsma JW, Conaghan PG, et al. Recommendations for the content and conduct of European League Against Rheumatism (EULAR) musculoskeletal ultrasound courses. Ann Rheum Dis 2008;67:1017-22. 
ARD Novel algorithms for the pragmatic use of ultrasound in the management of patients with rheumatoid arthritis: from diagnosis to remission

Maria Antonietta D'Agostino, Lene Terslev, Richard Wakefield, Mikkel Østergaard, Peter Balint, Esperanza Naredo, Annamaria lagnocco, Marina Backhaus, Walter Grassi and Paul Emery

Ann Rheum Dis 2016 75: 1902-1908 originally published online August 23, 2016

doi: 10.1136/annrheumdis-2016-209646

Updated information and services can be found at:

http://ard.bmj.com/content/75/11/1902

\section{Notes}

\section{These include:}

References This article cites 77 articles, 40 of which you can access for free at: http://ard.bmj.com/content/75/11/1902\#BIBL

Email alerting Receive free email alerts when new articles cite this article. Sign up in the service box at the top right corner of the online article.

To request permissions go to:

http://group.bmj.com/group/rights-licensing/permissions

To order reprints go to:

http://journals.bmj.com/cgi/reprintform

To subscribe to BMJ go to:

http://group.bmj.com/subscribe/ 